\title{
PERAN PENYULUH PERTANIAN DALAM PENGGUNAAN PUPUK ORGANIK DI PROVINSI KALIMANTAN SELATAN
}

\author{
(Role of Agricultural Investors In Use Of Organic Fertilizer In South Kalimantan Province)
}

\author{
Andi Suci Anita ${ }^{1}$ dan Purna Kusumayana ${ }^{2}$ \\ ${ }^{1}$ Program Studi Agribisnis Universitas Terbuka Banjarmasin \\ ${ }^{2}$ Program Studi Agribisnis Sekolah Tinggi Ilmu Pertanian Amuntai \\ Jl. Sultan Adam No.128. Banjarmasin 70122 \\ Email : andisuci@ecampus.ut.ac.id
}

Article Submitted : 12-12-2018

Article Accepted : 25-01-2019

\begin{abstract}
Information dissemination through agricultural extension workers can increase knowledge, can change behavior, and attitudes of farmers, especially regarding the use of organic fertilizers. Changes in behavior and attitudes can be seen from the participation of farmers in using organic fertilizers. Participation through the participation of farmers can be a more efficient way to achieve the stated goals. The aim of this study was to examine the role of agricultural extension agents in the use of organic fertilizers in the Province of South Kalimantan. Measurement of the role of agricultural extension agents in the use of organic fertilizer using the median score. The role of agricultural extension agents in the use of organic fertilizers includes: the role of agricultural extension agents as motivators, mediators and supervisors. The role of agricultural extension agents as motivators in the use of organic fertilizers gets a median score of 4 , which means that agricultural instructors are eager to encourage farmers to use organic fertilizers due to a fairly good farmer response so that extension workers can motivate farmers to use organic fertilizer. The role of agricultural extension agents as mediators in the use of organic fertilizers gets a median score of 4, meaning that the tasks of agricultural extension agents as mediators have been carried out well. Information or policies from related government or extension agencies are delivered by extension agents to farmers, both through regular meetings and incidental meetings. While the role of agricultural extension agents as supervisors in the use of organic fertilizers has a median score of 5 which means that the role of agricultural extension agents has been carried out to the maximum seen from the frequency of implementation of guidance by extension agents.
\end{abstract}

Keywords: Role, Agricultural Extension, Organic Fertilizer

\section{PENDAHULUAN}

Kesuksesan Indonesia dalam hal swasembada, salah satu faktor tersebut karena besarnya peran penyuluh pertanian lapangan (PPL). Sebab, PPL memberikan pembinaan dan informasi kepada para petani bagaimana cara meningkatkan produksi.Selain itu, PPL juga memberikan informasi terkait teknologi pertanian terbaru dan cara menggunakannya (Prahara, 2017).
Dalam budidaya tanaman, pemupukan merupakan hal penting karena ini sangat menentukan keberhasilan tanaman.Pemupukan bertujuan untuk mencukupi unsur hara yang diperlukan tanaman.Pupuk dapat dikatakan sebagai bahan-bahan yang diberikan pada tanah agar dapat menambah unsur-unsur atau zat makanan yang diperlukan tanah baik secara langsung maupun tidak langsung. Secara 
umum pupuk hanya dibagi dalam dua kelompok berdasarkan asalnya yaitu: (a) Pupuk anorganik seperti urea (pupuk N), TSP atau SP-36 (pupuk P) dan $\mathrm{KCl}$ (pupuk K) (2) Pupuk organik seperti pupuk kandang, kompos, humus dan pupuk hijau.

Usaha yang dilakukan untuk memperbaiki kesuburan tanah adalah dengan melakukan pemupukan menggunakan pupuk organik. Kandungan unsur hara dalam pupuk kandang tidak terlalu tinggi, tetapi jenis pupuk ini mempunyai lain yaitu dapat memperbaiki sifat - sifat fisik tanah seperti permeabilitas tanah, porositas tanah, struktur tanah, daya menahan air dan kation - kation tanah.

Dalam penggunaan pupuk organik, diperlukan penyebaran informasi pertanian mengenai pupuk organik dari penyuluh pertanian kepada petani, agar petani dapat mengetahui dan memahami serta dapat menggunakan pupuk organik.Pengetahuan dapat diperoleh apabila penyampaian informasi dari penyuluh pertanian jelas dan berjalan dengan lancar.Penyebaran informasi melalui penyuluh pertanian dapat meningkatkan pengetahuan, dapat merubah perilaku, dan sikap petani khususnya tentang penggunaan pupuk organik.Perubahan perilaku dan sikap dapat dilihat dari partisipasi petani dalam menggunakan pupuk organik. Partisipasi melalui pengikutsertaan petani dapat menjadi cara yang lebih efisien untuk mencapai tujuan yang telah ditetapkan.

Petani adalah setiap orang yang melakukan usaha untuk memenuhi sebagian atau seluruh kebutuhan hidupnya dibidang pertanian dalam arti luas yang meliputi usaha tani pertanian, peternakan, perikanan (termasuk penangkapan ikan) dan pemungutan hasil laut. Peranan petani sebagai pengelola usaha tani berfungsi mengambil keputusan dalam mengorganisasi faktor-faktor produksi yang diketahui (Hernanto, 1993).

Petani memanfaatkan berbagai sumber untuk mendapatkan pengetahuan dan informasi yang mereka perlukan untuk mengelola usaha tani mereka dengan baik, yang meliputi: petani-petani lain, organisasi penyuluhan milik pemerintah, perusahaan swasta yang menjual, input, menawarkan kredit, dan membeli hasil pertanian, agen pemerintah yang lain, lembaga pemasaran dan politisi, organisasi petani dan organisasi swasta beserta stafnya, jurnal usaha tani, televisi, radio, dan media massa lainnya, konsultan swasta, pengacara, dan dokter hewan (Hawkins dan Van den Ban, 1999).

Rumusan masalah dalam penelitian ini adalah bagaimana peran penyuluh pertanian dalam penggunaan pupuk organik di Kalimantan Selatan. Berdasarkan latar belakang dan perumusan masalah, maka tujuan yang ingin dicapai dalam penelitian ini adalah untuk mengkaji peran penyuluh pertanian dalam penggunaan pupuk organik di Kalimantan Selatan.

\section{METODE PENELITIAN}

Penelitian dilakukan di beberapa kabupaten di Kalimantan Selatan yaitu Kabupaten Barito Kuala, Kabupaten Banjar dan Hulu Sungai Utara pada Bulan April 2018 sampai dengan Bulan Agustus 2018.

Metode pengumpulan data yang digunakan adalah "multistage random sampling" dikarenakan areal lokasi yang terlampau luas. Tahapan pertama dipilih dengan sengaja tiga kabupaten yang mewakili penduduk yang jumlah penduduk banyak, sedang, dan sedikit. Dalam hal ini dipihlah Kabupaten barito Kuala, Kabupaten Banjar dan Kabupaten Hulu Sungai Utara. Tahap kedua pengambilan sampel dengan random sampling artinya bahwa responden diambil secara acak dari keseluruhan petani yang melakukan penggunaan pupuk organik di tiga kabupaten tersebut dengan metode slovin.

\section{HASIL DAN PEMBAHASAN}

Penyuluhan pertanian adalah proses untuk memberikan penerangan kepada masyarakat (petani) tentang segala sesuatu 
yang "belum diketahui (dengan jelas)" untuk dilakukan/diterapkan dalam rangka peningkatan produksi dan pendapatan/keuntungan yang ingin dicapai melalui proses pembangunan pertanian (Mardikanto, 1993).

Seorang penyuluh harus berjiwa sebagai pendidik yang dapat menimbulkan perubahan-perubahan pengetahuan, kecakapan, sikap, dan ketrampilanpada para petani yang disuluhnya. Selain itu ia harus berjiwa pemimpinyaitu cakap dan mampu mengarahkan perhatian para petani kepada yangdikehendaki dan diharapkannya, cakap dan mampu menggerakkankegiatan para petani kearah kegiatan yang lebih baik dan lebihmenguntungkan, cakap dan mampu memberi dorongan dan semangatkerja para petani, memanfaatkan para pemuka atau tokoh tani untukmengembangkan materi penyuluhannya. Berjiwa sebagai penasihat yangdalam hal ini penyuluh harus cakap, mampu dengan penuh kesabaran danketekunan menjalin jiwa kekeluargaan dengan para petani agar dapatbertindak sebagai penasihat, pemberi petunjuk dan membantu para petanidalam menghadapi dan memecahkan persoalan-persoalan yang berkaitan dalam usaha taninya (Kartasapoetra, 1994).

Adanya suatu penemuan baru baik berupa ide maupun teknologi memerlukan suatu media dimana penemuan baru tersebut dapat dikomunikasikan ke sasarannya. Penyuluh pertanian merupakan komunikator yang memegang peran penting agar penemuan baru di bidang pertanian dapat sampai ke sasaranya. Adapun peran penyuluh yang digunakan dalam penelitian ini adalah peran penyuluh sebagai motivator, mediator, dan supervisor. Untuk menentukan peranan penyuluh pertanian dalam kategori sangat baik, baik, sedang, buruk, sangat buruk dengan menggunakan median skor.

\section{Peran Penyuluh Pertanian sebagai Motivator}

Penyuluh sebagai motivator menurut Havelock dan Daud (2011) yaitu kemampuan penyuluh untuk menumbuhkan dan mengembangkan kepercayaan petani, medorong, mengaktifkan, menggerakkan dan mengarahkan perilaku kelompok sasaran (petani) agar mau mengemukakan pendapat, keinginan dan pengetahuan dan masalah yang dihadapinya.

Peran penyuluh pertanian sebagai motivator merupakan peran penyuluh dalam mendorong semangat petani dan mempengaruhi petani agar tergerak untuk menggunakan pupuk organik pada tanaman padi. Dalam penelitian ini, peran penyuluh pertanian sebagai motivator dilihat dari frekuensi penyuluh dalam memberikan motivasi kepada petani untuk menggunakan pupuk organik dalam usahataninya. Peran penyuluh sebagai motivator di Kalimantan Selatan secara rinci dapat dilihat pada tabeltabel berikut ini.

Tabel 1. Peran Penyuluh Pertanian Sebagai Motivator di Provinsi Kalimantan Selatan

\begin{tabular}{llccc}
\hline Variabel & Kriteria & Jumlah (Orang) & Presentasi (\%) & Median \\
\hline Motivator & Sangat baik & 10 & 10 & \\
& Baik & 65 & 65 & 4 \\
& Cukup baik & 14 & 14 & \\
& Buruk & 10 & 10 & \\
\hline & Sangat Buruk & 1 & 1 & \\
& Jumlah & 100 & 100 & \\
\hline
\end{tabular}

Sumber : Data Primer (diolah) 2018

Berdasarkan dari Tabel 1 dapat diketahui bahwa peran penyuluh pertanian sebagai motivator di Provinsi Kalimantan Selatan mendapatkan median skor 4 berada 
dalam kategori baik. Peran penyuluh pertanian sebagai motivator dalam kategori baik mengindikasikan bahwa penyuluh pertanian sangat memberikan dorongan serta semangat kepada petani untuk menggunakan pupuk organik. Dorongan yang kuat dan semangat dari penyuluh diakibatkan karena adanya respon petani yang cukup baik sehingga penyuluh dapat memotivasi petani untuk menggunakan pupuk organik.

Penyuluh memotivasi petani untuk menggunakan pupuk organik tidak hanya cukup dengan membangkitkan semangat pribadinya mengikuti penyuluhan, tetapi dengan cara menyampaikan bagaimana jangkauan keberhasilan dari penggunaan pupuk organik. Pemberian materi tentang jangkauan keberhasilan pupuk organik menurut responden mampu memotivasi petani untuk menggunakan pupuk organik. Selain itu, penyuluh pertanian juga mengajak petani untuk mengetahui jangkauan keberhasilan pupuk organik dengan melakukan kunjungan lapang ke daerah yang telah menggunakan pupuk organik ataupun ke daerah yang menjadi demplot, tetapi banyak petani yang tidak ikut kunjungan lapang dengan pertimbangan bahwa daerahnya terlalu jauh sehingga memerlukan biaya yang cukup besar bagi petani.

\section{Peran Penyuluh Pertanian sebagai Mediator}

Penyuluh sebagai mediator atau jembatan penghubung antara petani dan lembaga penelitian. Penyuluh bertugas untuk menyampaikan hasil temuan lembaga penelitian kepada petani. Sebaliknya petani berkewajiban melaporkan hasil pelaksanaan penerapan hasil-hasil temuan lembaga penelitian yang dianjurkan tersebut kepada penyuluh yang membinanya sebagai jembatan penghubung, selanjutnya penyuluh menyampaikan hasil penerapan teknologi yang dilakukan oleh petani kepada lembaga penelitian yang terkait sebagai bahan referensi lebih lanjut (Suhardiyono, 1989).

Peran penyuluh pertanian sebagai mediator merupakan peran penyuluh dalam menghubungkan petani dengan sumber informasi dalam memecahkan masalah yang dihadapi dalam menggunakan pupuk organik. Adapun peran penyuluh sebagai mediator dapat diukur dariindikator menghubungkan sumber informasi dengan petani, proses pemecahan masalah, dan pembuatan pupuk. Peran penyuluh sebagaimediator secara rinci dapat dilihat pada Tabel 2 berikut.

Tabel 2. Peran Penyuluh Pertanian Sebagai Mediator di Provinsi Kalimantan Selatan

\begin{tabular}{llccc}
\hline Variabel & Kriteria & Jumlah (Orang) & Presentasi (\%) & Median \\
\hline Mediator & Sangat baik & 27 & 27 & \\
& Baik & 48 & 48 & 4 \\
& Cukup baik & 17 & 17 & \\
& Buruk & 8 & 8 & \\
& Sangat Buruk & 0 & 0 & \\
\hline
\end{tabular}

Sumber : Data Primer (diolah) 2018

Dari Tabel 2 dapat diketahui bahwa peran penyuluh pertanian sebagai mediator di Proinsi Kalimantan Selatan berada dalam kategori baik dengan median skor 4 . Peran penyuluh pertanian sebagai mediator dalam kategori baik mengindikasikan bahwa tugastugas penyuluh pertanian sebagai mediator sudah dijalankan dengan baik. Informasi ataupun kebijakan dari pemerintah atau lembaga penyuluhan terkait disampaikan oleh penyuluh kepada petani, baik melalui pertemuan rutin maupun pertemuan insidental. Pertemuan rutin diadakan setiap sebulan sekali, sedangkan pertemuan 
insidental adalah pertemuan yang diadakan di luar jadwal pertemuan rutin.

Peran Penyuluh Pertanian sebagai Supervisor

Peran penyuluh pertanian sebagai supervisor penyuluh yaitu dalam melakukan pembinaan terhadap pemupukan, peran penyuluh sebagai supervisor dapat diukur dari indikator pelaksanaan supervisi (Indah, Supervisi diperlukan dalam pemupukan untuk mengetahui apakah pemupukan yang dilakukan petani sudah tepat. Peran penyuluh sebagai supervisor secara rinci dapat dilihat pada Tabel 3 berikut.

Tabel 3. Peran Penyuluh Pertanian Sebagai Supervisor di Provinsi Kalimantan Selatan

\begin{tabular}{llccc}
\hline Variabel & Kriteria & Jumlah (Orang) & Presentasi (\%) & Median \\
\hline Supervisor & Sangat baik & 52 & 52 & \\
& Baik & 31 & 31 & 5 \\
& Cukup baik & 8 & 8 & \\
& Buruk & 7 & 7 & \\
& Sangat Buruk & 2 & 2 & \\
\hline
\end{tabular}

Sumber : Data Primer (diolah) 2018

Berdasarkan tabel 3 dapat diketahui bahwa peran penyuluh pertanian sebagai supervisor dalam kategori sangat baik atau tinggi dengan median skor 5. Peran penyuluh pertanian sebagai supervisor dalam kategori tinggi mengindikasikan bahwa tugas-tugas penyuluh pertanian sebagai supervisor sudah dijalankan secara maksimal. Dilihat dari frekuensi pelaksanan pembinaan oleh penyuluh tergolong sangat tinggi. Hal ini dikarenakan fasilitas sudah tercukupi dan sangat memadai baik ketrampilan, tenaga supervisor maupun sarana pendukungnya.

Dapat dilihat bahwa peran penyuluh sangat berat, mengharuskannya memiliki kemampuan tinggi, Oleh karena itu, kualitas dari penyuluh harus terus ditingkatkan sehingga mampu berperan dalam memberikan penyuluhan dan mewujudkan pembangunan pertanian.Peranan agen penyuluhan pertanian adalah membantu petani membentuk pendapat yang sehat dan membuat keputusan yang baik dengan cara berkomunikasi dan memberikan informasi yang sesuai dengan kebutuhan petani. Peranan utama penyuluhan lebih dipandang sebagai proses membantu petani untuk mengambil keputusan sendiri dengan cara menambah pilihan bagi mereka, dan menolong petani mengembangkan wawasan mengenai konsekuensi dari masing-masing pilihan tersebut.

\section{KESIMPULAN DAN SARAN}

\section{Kesimpulan}

Peran penyuluh pertanian dalam penggunaan pupuk organik di Indonesia meliputi :peran penyuluh pertanian sebagai motivator, mediator, dan supervisor.

a. Peran penyuluh pertanian sebagai motivator dalam penggunaan pupuk organik di Kalimantan Selatan skor median 4 yang artinya penyuluh pertanian semangat mendorong petani menggunakan pupuk organik diakibatkan karena adanya respon petani yang cukup baik sehingga penyuluh dapat memotivasi petani untuk menggunakan pupuk organik.

b. Peran penyuluh pertanian sebagai mediator dalam penggunaan pupuk organik di Kalimantan Selatan skor median 4. Ini berarti bahwa tugas-tugas penyuluh pertanian sebagai mediator sudah dijalankan dengan baik. Informasi ataupun kebijakan dari pemerintah atau lembaga penyuluhan terkait disampaikan oleh penyuluh kepada petani, baik 
melalui pertemuan rutin maupun pertemuan insidental.

c. Peran penyuluh pertanian sebagai supervisor dalam penggunaan pupuk organik di Kalimantan Selatan skor median 5. Ini berarti peran penyuluh pertanian sudah dijalankan dengan maksimal dilihat dari frekuensi pelaksanan pembinaan oleh penyuluh.

\section{Saran}

Perlu adanya peningkatan kapasitas penyuluhan yang dilakukan oleh Dinas Pertanian setempat yang berkaitan dengan penyuluhnya, baik itu segi kemampuan penyuluh atau yang berkaitan dengan peningkatan jumlah tenaga penyuluh dan penyuluh pertanian perlu meningkatkan perannya sebagai motivator untuk mendorong semangat petani menggunakan pupuk organik.

\section{DAFTAR PUSTAKA}

Departemen Pertanian, 2006. UndangUndang Republik Indonesia Nomor 16 Tahun 2006 Tentang Sistem Penyuluhan Pertanian, Perikanan dan Kehutanan, Jakarta.

Hawkins, H.S., A.W. van den Ban. 1999. Penyuluhan Pertanian.Kanisius. Yogyakarta.

Hernanto, F. 1993. Ilmu Usaha Tani. Penebar Swadaya. Jakarta.

Kartasapoetra. 1991. Teknologi Penyuluhan Pertanian. Radar Jaya Offset. Jakarta.
Lingga, Pinus. 2002. Petunjuk Penggunaan Pupuk. Penebar Swadaya. Jakarta.

Mangkuatmodjo, Soegyarto. 2004. Statistik Lanjutan. PT. Rineka Cipta. Jakarta.

Mardikanto, T. 2003. Penyuluhan Pembangunan Pertanian. UNS Press. Surakarta.

Mardianto. 2005. Konsep dan Penerapan Perhutanan Sosial. PusatPengembangan Agrobisnis dan Perhutanan Sosial.Sukoharjo.

Prahara, Haris. 2017. "Sektor Pertanian dan Citra Indonesia di Mata Dunia", http://ekonomi.kompas.com/read/201 7/09/30/132000326/sektor-pertaniandan-citra-indonesia-di-mata-dunia.

Sevilla, Consuelo G. et. al (2007). Research Methods. Rex Printing Company. Quezon City.

Suhardiyono. 1989. Penyuluhan Petunjuk Bagi Penyuluh Pertanian. Erlangga.

Sulanjana, Agung dkk. 2005. Makalah Industri Pupuk dan Amonia. Bandung; Jurusan Pendidikan Kimia FPMIPA UPI.

Supadi.2007. Dinamika Partisipasi Petani Padi Sawah Peserta Program Peningkatan Mutu Intensifikasi (PMI) Di http://pse.litbang.deptan.go.id. 